greater than any oral information previously received.

I found myself thinking more carefully before I wrote notes and allowing patients access enabled details to be corrected and a more accurate record to be made. It was still possible to record sensitive information if it was correct.

The Access to Health Records Act may make little difference in practice, as our experience was that patients themselves rarely asked to read their notes. However, perhaps we should take the more radical step of offering and encouraging access. The major drawback is that it takes time adequately to explain psychiatric jargon and answer questions raised, but it is certainly time well spent.

Bexley Hospital

HILARY Foster

Bexley, Kent DA5 2BW

The Public Records Act, 1958, and local archive services

DeAR SirS

Psychiatrists who have a concern about the preservation of hospital documents and records will find the provisions of the Public Records Act, 1958, helpful. This Act places a duty on health authorities to preserve those classes of records deemed worthy of permanent preservation. Records less than 30 years old are the responsibility of the health authority and those over 30 years old of the Lord Chancellor's Department.

In practice, the Public Record Office asks a local record office to locate and care for the significant hospital records in its area. The records most at risk, for example at hospitals facing closure, are usually given priority for assessment and transfer. There is no change in the ownership of records deposited under the Act and if deposited records are needed by a hospital they are returned. There is no charge for the service although a free service may not exist for ever. Mental health seems to be an increasingly popular topic for students, but they are not permitted to see 'closed' medical records.

Psychiatrists seeking more information will no doubt find advice from their local archive service.

DOUglas A. SPENCER

Meanwood Park Hospital

Leeds LS6 4QB

\section{Pre-interview questionnaires}

\section{Dear Sirs}

We read the audit article on pre-interview questionnaires (Eynon \& Gladwell, Psychiatric Bulletin, March 1993, 17, 149-151) with interest.
In a recent study we examined the use of preinterview questionnaires by a child and family psychiatric unit. We found that the introduction of a pre-interview family questionnaire had significantly reduced the number of families who 'survive' the referral process and attend their first appointment. In parallel with Eynon \& Gladwell we identified other functions provided by pre-interview questionnaires, apart from that of information gathering. The very act of getting families to answer questions about the nature of their problems might in itself be a catalyst for change, thus removing the need for any professional intervention. The type of questions asked may act to deter those families who would find it difficult to engage and use the type of service that we provide. The hurdle described by Eynon \& Gladwell may indeed be too high for families in a state of chaos or crisis but who might otherwise have benefited from our type of service.

Proper evaluation of these latent functions - the therapeutic, the deterrent, and the hurdle-require studies of two types. Initially, recipients who fail to return their questionnaires will need to be contacted directly and an attempt made to find out why. Subsequently, pre-selection of patients in this way will need to be correlated with outcome criteria before we can justify deterring any sub-group of those individuals or families referred to us.

STUART COX
CLARE LUCEY
Children and Families Mental Health Service
Walpole House
13 Mattock Lane, Ealing W5

\section{Consumer audit of psychiatric training}

\section{DEAR SIRS}

I read with interest Cunningham \& Aquilina's paper on consumer audit of psychiatric training (Psychiatric Bulletin, February 1993, 17, 93-94) but am surprised that they are unaware of previous attempts by trainees to assess the quality of their training. Fahy \& Beats (1990) described a survey of junior psychiatrists' experiences at the Maudsley which seemed to address similar issues. They also discussed the long history of trainee assessment of psychiatric training quoting Jeffreys \& Murray's study conducted in 1974 !

The authors can be forgiven for being unaware of current trainee led audits of psychiatric training. On the Mid-Trent (Nottingham) rotation the Feedback on Jobs Committee, a sub-committee of the Junior Medical Staff Committee, has been engaged in a programme of regular audit for over six years. At six monthly intervals the trainees on the rotation (currently 17 SHOs, 25 registrars and four PM79/3 